\title{
A rare case of palatin tonsillar metastasis from small cell lung cancer
}

\author{
Chiara D'Antonio ${ }^{1}$, Alberto Lombardini ${ }^{1}$, Concetta Elisa Onesti ${ }^{1}$, Rosa Falcone ${ }^{1}$, Adriana Romiti ${ }^{1}$, \\ Marianna Lombardi ${ }^{2}$, Salvatore Lauro ${ }^{1}$, Paolo Marchetti ${ }^{1}$ \\ ${ }^{1}$ Department of Medical Oncology, ${ }^{2}$ Department of Anatomopathology, Sant'Andrea Hospital, Faculty of Medicine and Psicology, "Sapienza" \\ University of Rome, Via di Grottarossa 1035-39, 00189, Rome, Italy \\ Correspondence to: Concetta Elisa Onesti. Department of Medical Oncology, Sant'Andrea Hospital, Faculty of Medicine and Psicology, "Sapienza" \\ University of Rome, Via di Grottarossa 1035-39, 00189, Rome, Italy. Email: elisaonesti@gmail.com.
}

\begin{abstract}
Tonsillar metastases are absolutely rare. Small cell lung cancer (SCLC) is known to be the most frequent histological type of tonsillar metastases, however the way of tumor cells spreading to tonsil remains controversial. We described a case report of 76-year-old man with SCLC and tonsillar metastases, to highlight the importance of oral cavity evaluation as a part of a clinical exam and to show the rare tumor cells spreading.
\end{abstract}

Keywords: Small cell lung cancer (SCLC); palatin tonsillar metastasis; tonsillar cancer

Submitted Aug 22, 2016. Accepted for publication Sep 19, 2016.

doi: $10.21037 /$ tlcr.2016.11.07

View this article at: http://dx.doi.org/10.21037/tlcr.2016.11.07

\section{Introduction}

Tonsillar metastases are absolutely rare: in a series of 1,547 tonsillar tumors only $12(0.8 \%)$ were metastases (1). Similar results were reported in another study published by Hyams and colleagues (2). Overall few cases of lung cancers with tonsillar metastasis were described and the majorities were small cell lung cancer (SCLC) (3-8).

\section{Case presentation}

A 76 years old man was admitted at our emergency department because of dyspnea, associated to strep throat and difficulty swallowing, on April 2011. He was a former smoker of 30-40 cigarettes a day. His medical history included pulmonary emphysema, rickettsiosis, gouty arthritis, bilateral hypoacusis and cataract.

A total body computed tomography (CT) scan revealed a solid mass of $3.5 \mathrm{~cm}$ in the left upper lobe, mediastinal lymphadenopathy and pleural effusion, without lesions in the bone, brain, liver and adrenal glands.

Pathologic diagnosis of SCLC was obtained from a bronchoscopy with biopsy. Contextually, a large formation next to the lateral right portion of the tongue was even detected. A head and neck MRI disclosed a large mass arising from the right tonsil, displacing the soft palate (Figure 1). An incisional biopsy of tonsillar lesion showed a metastasis from SCLC. Hematoxylin and eosinstained sections revealed small carcinoma cells with scant cytoplasm and frequent mitotic figures (Figure 2). Immunohistochemical analysis resulted positive for neural cell adhesion molecule (CD56) and thyroid transcription factor-1 in tumor cells (Figures 3,4).

The patient received a chemotherapy regimen including carboplatin (AUC 6) day 1 and etoposide $(100 \mathrm{mg} / \mathrm{mq}$ ) day $1-3$, q21. A stable disease lasting 6 months was detected by a whole body CT scan. However, a further CT scan, revealed brain metastases 3 months after the end of chemotherapy. The patients received a whole-brain radiotherapy followed by a second line chemotherapy with topotecan $(1.5 \mathrm{mg} / \mathrm{mq}$ day 1-5 q21).

Finally, patient died for progressive disease 3 months later, with an overall survival of 14 months.

\section{Discussion}

SCLC is known to be the most frequent histological type of tonsillar metastases, however the way of tumor 


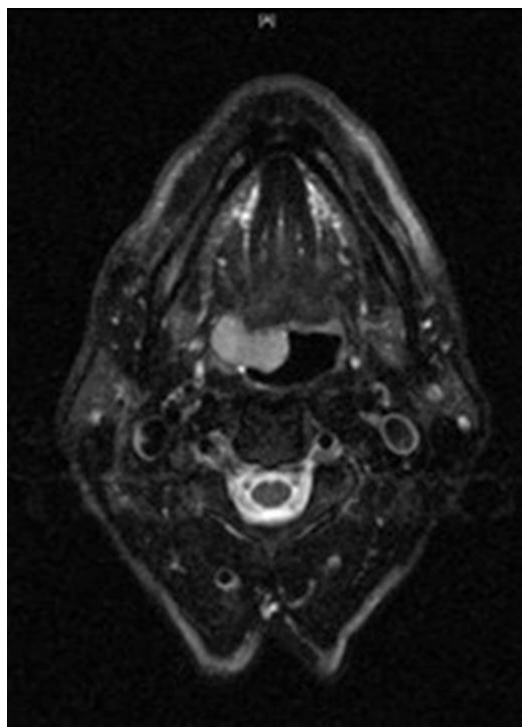

Figure 1 T2 weighted MRI scan of the oropharynx showing the small cell lung cancer (SCLC) right palatin tonsil metastasis that appears strongly hyperintense if compared with striated muscles and easily delimitable.

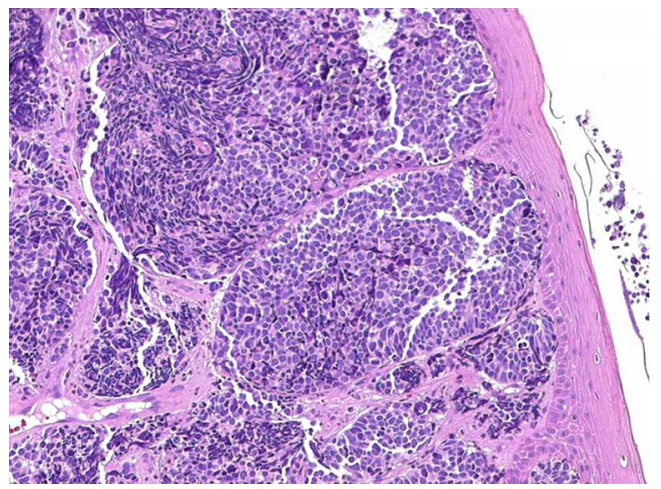

Figure 2 Hematoxylin and eosin picture $(100 \times)$ of the tissue section, showing a minute fragment of tissue within the infiltration of small cell carcinoma with high mitotic activity.

cells spreading to tonsil remains controversial. Both hematogenous and retrograde lymphatic spreading of cancer cells can be considered (7). Prognosis of patients with tonsillar metastasis remains poor. The paucity of casuistic prevented to have effective treatments. Nonetheless, recently Gottschling and colleagues reported a long-term response to gefitinib in a KRAS-mutation positive, metastatic tonsil carcinoma with cancer stem-like cell features (8).

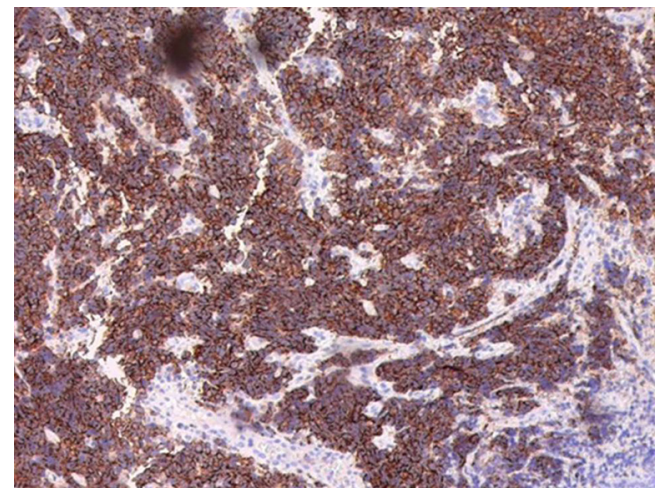

Figure 3 Image of the tissue section $(100 \times)$ stained with antiCD56 monoclonal antibody, showing high and uniform positivity of virtually all cells of the tumor.

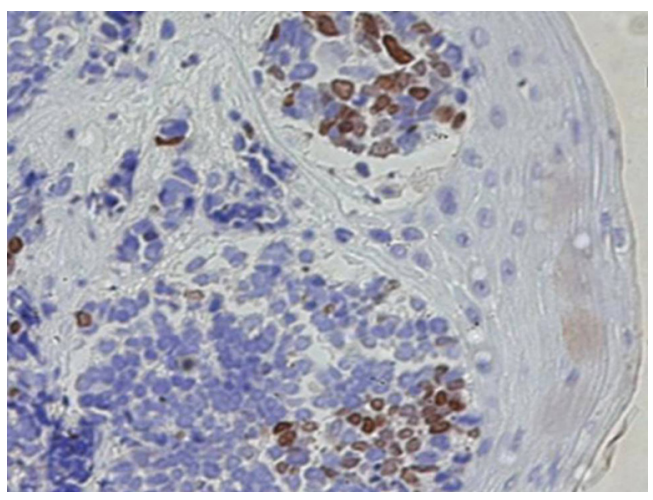

Figure 4 Image of the tissue section $(100 \times)$ stained with monoclonal anti-TTF1, showing focal nuclear positivity of the tumor.

We reported a case of synchronous tonsillar metastases in a SCLC patient with a similar survival compared to patients previously evaluated. For the purpose of a complete staging in cancer patients, especially in those with SCLC, we would highlight the importance of oral cavity evaluation as a part of a clinical exam.

\section{Acknowledgements}

None.

\section{Footnote}

Conflicts of Interest: The authors have no conflicts of interest to declare. 
Informed Consent: Written informed consent was obtained from the patient for publication of this manuscript and any accompanying images.

\section{References}

1. Crawford BE, Callihan MD, Corio RL, et al. Oral pathology. Otolaryngol Clin North Am 1979;12:29-43.

2. Hyams VJ. Differential diagnosis of neoplasia of the palatine tonsil. Clin Otolaryngol Allied Sci 1978;3:117-26.

3. Mastronikolis NS, Tsiropoulos GE, Chorianopoulos D, et al. Palatine tonsillar metastasis from lung adenocarcinoma. Eur Rev Med Pharmacol Sci 2007;11:279-82.

4. Kim EJ, Kim SR, Jin Gang S, et al. Tonsillar metastasis of small cell lung cancer in a patient with idiopathic

Cite this article as: D'Antonio C, Lombardini A, Onesti CE, Falcone R, Romiti A, Lombardi M, Lauro S, Marchetti P. A rare case of palatin tonsillar metastasis from small cell lung cancer. Transl Lung Cancer Res 2016;5(6):709-711. doi: 10.21037/tlcr.2016.11.07 pulmonary fibrosis: a case report. Medicine (Baltimore) 2015;94:e565.

5. Unsal M, Kutlar G, Sullu Y, et al. Tonsillar metastasis of small cell lung carcinoma. Clin Respir J 2016;10:681-683.

6. Arroyo HH, Takehara J, Ogawa AI, et al. Small cell lung carcinoma metastasis to palatine tonsils. Braz J Otorhinolaryngol 2013;79:645.

7. Seddon DJ. Tonsillar metastasis at presentation of small cell carcinoma of the lung. J R Soc Med 1989;82:688.

8. Gottschling S, Penzel R, Pelz T, et al. KRAS-mutation positive, metastatic tonsil carcinoma with cancer stemlike cell features and long-term response to gefitinib: a case report and review of the literature. J Clin Oncol 2011;29:e616-9. 